\title{
PENELITIAN DAN PENGEMBANGAN CHAIR BREASTFEEDING UNTUK MENINGKATKAN KENYAMANAN PROSES MENYUSUI
}

\author{
Feni Nofalia Safitri' ${ }^{1}$, Teti Isnawati ${ }^{1}$, Ari Hermawan', Yolanda Pingka Rani ${ }^{1}$, Happy Dwi Aprilina ${ }^{1}$ \\ 1'Departemen Keperawatan Maternitas, Universitas Muhammadiyah Purwokerto, Jawa Tengah \\ Email : feninofaliasafitri@gmail.com
}

\begin{abstract}
ABSTRAK
Latar Belakang: Proses menyusui membutuhkan waktu yang lama, sehingga membuat ibu merasa pegal karena harus menompang bayi. Chair Breastfeeding merupakan kursi yang dapat mengurangi keluhan ibu saat menyusui. Saat ini, chair breastfeding sudah ada namun dari segi desain kurang ergonomis karena pada sandaran punggung dan sandaran lengan tidak terbalut busa dan kain katun halus, serta tidak terdapat pijakan kaki. Chair breastfeding yang ada saat kurang menarik dan kurang ergonomis sehingga daya jual rendah.

Tujuan: Penelitian ini bertujuan untuk meneliti dan mengembangkan chair breastfeeding yang sesuai dengan ergonomis bagi ibu menyusui sehingga membantu meningkatkan proses menyusui.

Metode: Penelitian ini merupakan jenis penelitian yang mengadopsi penelitian Research and Development (R\&D). Penelitian ini terdiri dari 3 tahap, yaitu penelitian tahap I, tahap development, dan penelitian tahap II atau ujicoba produk.

Hasil: Hasil penelitian tahap I diperoleh hasil, dari 6 orang ibu menyusui mengatakan bahwa chair breastfeeding yang ergonomis bila terdapat sandaran punggung, sandaran lengan, dan pijakan kaki. Chair breastfeeding terbuat dari bahan yang kuat, kayu dilapisi busa dan tertutup oleh kain yang halus. Tahap development terbentuklah chair breastfeeding yang ergonomis sesuai dengan hasil penelitian tahap pertama, yaitu terdapat pijakan kaki yang menempel permanen pada kursi, sandaran punggung dan sandaran lengan yang dilapisi busa dan tertutup oleh kain katun halus dan penambahan setengah lingakaran di bagian depan untuk meringankan beban ibu saat menyusui serta ukuran yang disesuaikan dengan antropometri tubuh. Hasil penelitian tahap II diperoleh, 5 orang mengatakan chair breastfeeding ergonomis dan nyaman digunakan dalam proses menyusui, dan 1 orang mengatakan tidak ergonomis dan kurang nyaman digunakan dalam proses menyusui.

Kesimpulan: Chair breastfeeding yang ergonomis terbukti dapat meningkatkan kenyamanan dalam proses menyusui
\end{abstract}

Kata Kunci: ASI; Chair Breastfeeding; Menyusui

\section{PENDAHULUAN}

Menyusui adalah proses pemberian Air Susu Ibu (ASI) kepada bayinya, dimana bayi memiliki refleks menghisap untuk mendapatkan dan menelan ASI. Menyusui merupakan proses alamiah yang keberhasilannya tidak diperlukan alat-alat khusus dan biaya yang mahal namun membutuhkan kesabaran, waktu, dan pengetahuan tentang menyusui serta dukungan dari lingkungan keluarga terutama suami (Roesli, 2000). Menyusui dilakukan selama bayi mau, rata-rata sampai 15 sampai
30 menit pada beberapa minggu pertama (WHO, 2011).

Pada saat menyusui ibu biasanya harus duduk minimal 20 menit, karena rentang waktu cukup untuk bayi dan ibu terpaksa untuk memposisikan diri dan bayi secara tepat agar proses menyusui dapat berjalan lancar. Ibu akan dalam posisi tersebut berkali-kali setiap harinya sampai enam bulan atau lebih, kondisi tersebut akan menimbulkan sensasi ketidaknyamanan bagi ibu (Fahma, Farikhrina, dkk 2010).

Menurut Lowdermilk (2013) 
F N Safitri, T Isnawati, A Hermawan, Y P Rani, H D Aprilina | Penelitian dan Pengembangan Chair Breastfeeding untuk Meningkatkan Kenyamanan Proses Menyusui

menyatakan bahwa menyusui sebaiknya memperhatikan posisi dan pelekatan menyusui. Posisi dan pelekatan yang tidak tepat akan mengakibatkan bayi tersedak, ibu nyeri punggung bahkan bisa mengakibatkan putting lecet.

Posisi nyaman yang dilakukan ibu menyusui bayi yang berumur 0-2 tahun belum sesuai dengan posisi menyusui yang benar dalam keadaan duduk seperti terlalu membungkuk, jangkauan tangan dan kaki yang tidak normal. Hal tersebut sehingga mengakibatkan timbulnya berbagai permasalahan yaitu kelelahan dan rasa nyeri pada punggung akibat dari duduk yang tidak ergonomis tersebut (Suradi, 2004).

Hasil studi pendahuluan yang dilakukan pada 10 ibu menyusui bayinya yang berumur 0-2 tahun menggunakan posisi duduk, ditemukan 25\% ibu duduk menggunakan kursi/sofa dan 75\% ibu tidak duduk menggunakan kursi. Hasil kuesionaer Nordic Body Map yang telah diisi oleh ibu yang mengalami keluhan sakit, nyeri, kesemutan, dan lain-lain pada beberapa bagian tubuh yaitu leher (23\%), punggung bagian atas (23\%), punggung bagian bawah (17\%), lengan bawah (12\%), pergelangan tangan (10\%), bahu (10\%), dan pinggul (5\%). Indikator dalam proses menyusui yang efektif meliputi posisi ibu dan bayi yang benar (body position), perlekatan bayi yang tepat (latch), keefektifan hisapan bayi pada payudara (effective sucking) (Rinata, 2016).

Munculnya sensasi ketidaknyamanan pada posisi saat mnyusui diperkirakan karena prinsip ergonomis belum diterapkan. Salah satu penyelesaian maslah ketidaknyamanan dalam menyusui yaitu dengan adanya peralatan ergonomis berupa kursi menyusui. Tempat kerja dan peralatan yang ergonomis memperkecil banyaknya pergerakan tubuh dan membantu penyesuaian postural untuk mempertahankan postur tubuh dengan tetap (Dall'Oglio, 2007).

Tujuan ergonomis memaksimalkan kenyamanan dan dapat membantu mengurangi tekanan biomekanis pada tangan pekerja, bahu, dan lengan yang dapat menyebabkan gangguan. Oleh karena itu, perlu adanya penerapan ilmu ergonomi dalah aktivitas menyusui

Posisi duduk sangat penting sebagai dasar pola posisi ergonomis, terutama untuk Ibu menyusui perlu kenyamanan dalam proses menyusui, salah satunya dapat menggunakan kursi khusus untuk menyusui. Setiap ibu yang menyusui harus berada pada posisi yang tepat dan dalam kondisi nyaman karena mempengaruhi proses laktasi. Ibu dipaksa untuk memposisikan diri dan bayi secara tepat agar proses menusui dapat berjalan lancar.

Di Indonesia sudah terdapat berbagai macam produk kursi menyusui, namun bentuk dan desain kursi menyusui yang ada masih seperti kursi biasa, tidak memiliki sandaran kursi yang dilapisi busa dan pijakan kaki. Membuat ibu menyusui tidak terbantu penuh dan masih merasakan pegal-pegal ketika memeberikan ASI karena kursi yang tidak ergonomis.

Kursi menyusui yang saat ini ada di pasaran memiliki daya jual yang rendah karena bentuk desain kursi yang kurang ergonomis dan kurang menarik bagi ibu menyusui. Desain yang kurang ergonomis seperti sandaran punggung dan sandaran 
F N Safitri, T Isnawati, A Hermawan, Y P Rani, H D Aprilina | Penelitian dan Pengembangan Chair Breastfeeding untuk Meningkatkan Kenyamanan Proses Menyusui

lengan tidak terbalut busa dan kain katun halus dan tidak terdapat pijakan kaki sehingga menyebabkan ibu tidak nyaman saat menyusui dan mengalami nyeri pada punggung dan lengan.

Pengembangan kursi menyusui ini mendukung Peraturan Pemerintah Kesehatan Republik Indonesia Nomor 15 Tahun 2013 tentang tata cara penyediaan fasilitas khusus menyusui dan/atau memerah air susu ibu. Fasilitas dalam ruang ASI salah satunya kursi dengan sandaran, meja, wastafel, dan sabun cuci tangan. Di Kabupaten Banyumas sekitar $60 \%$ ada ruang laktasi di tempat umum seperti terminal, stasiun, pusat perbelanjaan; perusahaan/pabrik; dan perkantoran, namun ruang laktasi yang tersedia mempunyai fasilitas yang sederhana seperti kursi tanpa sandaran, meja, wastafel, dan sabun cuci tangan.

Oleh karena itu peneliti mengembangkan chair breastfeeding (kursi menyusui) sebagai upaya untuk mempertahankan kenyamanan posisi ibu dan bayi dalam proses menyusui. Chair breastfeeding merupakan inovasi baru yang menerapkan posisi ergonomis, dimana posisi badan ibu dan bayi dalam posisi mudah atau kembali dalam posisi netral.

Posisi netral ada ibu menyusui yaitu dimana otot dalam posisi yang cenderung rilex sehingga memudahkan ibu dalam proses menyusui. Chair breastfeeding dapat meringankan beban ibu untuk mengangkat bayi, memberikan kenyamanan kepada ibu dan bayi serta mempertahankan posisi ibu sehingga megurangi resiko nyeri pada lengan dan punggung ibu. Chair breastfeeding ini mempunyai harga yang bervariasi sehingga ibu menyusui dapat membelinya dengan mudah sesuai dengan tingkat ekonominya.

\section{METODE}

Penelitian ini merupakan jenis penelitian yang mengadopsi penelitian Research and Development (R\&D) (Sukmadinata, 2011; Sugiyono, 2009). Penelitian ini terdiri dari 3 tahap, yaitu Penelitian tahap I, development, dan penelitian tahap II atau ujicoba produk.

Tahap I merupakan penelitian deskriptif yang bertujuan untuk mengetahui kursi yang tepat menurut ibu menyusui desain yang digunakan adalah survey (Abdurrahmat, 2011). Penelitian ini dilakukan bulan April tahun 2018. Populasi dalam penelitian ini yaitu ibu menyusui di daerah Purwokerto. Sampel penelitian menggunakan 6 orang responden. Instrumen yang digunakan adalah kuesiner dan lembar wawancara, dimana wawancara yang direncanakan berdasarkan pedoman atau daftar pertanyaan yang telah dipersiapkan lebih dahulu mengenai keergonomisan chair breastfeeding. Data dianalisa dengan menggunakan analisis deskriptif sederhana.

Tahap ke 2 merupakan tahap development, atau tahap pembuatan chair breastfeeding yang tepat dengan mengacu hasil penelitian tahap 1. Peneliti merancang chair creastfeeding sesuai permintaan pasar dengan bentuk dan desain yang ergonomis bagi ibu menyusui. Chair breastfeeding yang dibuat dengan adanya sandaran punggung, lengan, pijakan kaki, serta dengan penambahan setengah lingkaran pada bagian kursi depan, akan meningkatkan keergonomisan ibu menyusui saat proses 
F N Safitri, T Isnawati, A Hermawan, Y P Rani, H D Aprilina | Penelitian dan Pengembangan Chair Breastfeeding untuk Meningkatkan Kenyamanan Proses Menyusui

menyusui (Sugiyono, 2009).

Tahap ke 3 merupakan tahap uji coba atau penelitian tahap 2. Jenis penelitian adalah mini eksperimental (Suryabrata, (2012). Populasi yang digunakan dalam penelitian ini ibu menyusui di daerah Purwokerto dengan jumlah sampel sebanyak 6 orang ibu menyusui. Variabel yang dinilai yaitu tingkat keergonomisan dan kenyakaman dalam menyusui dengan menggunkan chair creastfeeding. Instrumen yang digunakan dalam penelitian ini yaitu RULA (Rupid Upper Limb Assessment) (McAtamney L \& Nigel Corlett E, 1993), dan kuesioner berisi pertanyaan terstruktur mengeni kenyaman. Instrumen RULA menguji keefektifan chair breastfeeding terhadap keergonomisan proses ibu menyusui dilihat dari kenyamanan postur tubuh dan posisi tubuh saat duduk (Karwowski, 2006). Analisa data menggunakan analisis deskriptif sederhana.

\section{HASIL}

Penelitian tahap 1 memperoleh hasil, dari wawancara yang dilakukan terhadap 6 ibu menyusui manyatakan kursi menyusui yang sudah ada bentuk dan desain kurang ergonomis karena pada sandaran punggung dan sandaran lengan tidak terbalut busa dan kain katun halus, serta tidak terdapat pijakan kaki. Seluruh responden menyatakan kursi menyusui yang bagus adalah yang nyaman pada saat menyusui, tidak menimbulkan kelelahan dan empuk.

Pada tahap development diperoleh desain dan bentuk produk sesuai dengan keinginan pasar yang terdapat pada gambar 1 berikut:

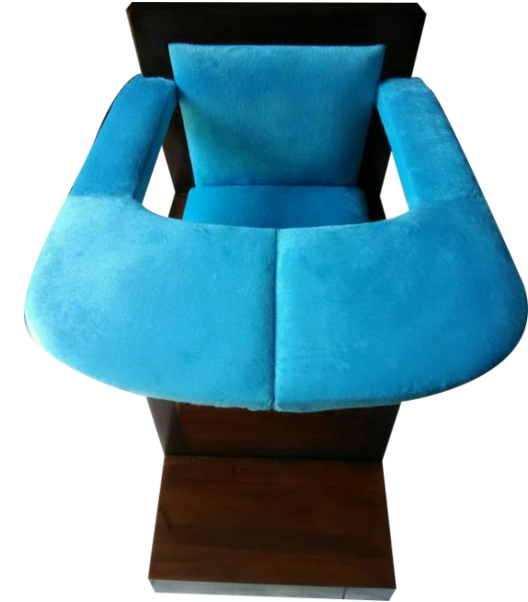

Gambar 1. Chair Breastfeeding

Gambar 1 menunjukkan desain produk chair breastfeeding yang menarik dengan ukuran yang disesuaikan dengan antropometri tubuh. Tinggi posisi duduk 90 $\mathrm{cm}$, tinggi siku pada posisi duduk $32 \mathrm{~cm}$, tinggi Lipatan dalam lutut $50 \mathrm{~cm}$, panjang pantat hingga lipatan dalam lutut $53 \mathrm{~cm}$, ketebalan bantal $4 \mathrm{~cm}$, lebar bahu $53 \mathrm{~cm}$, lebar panggul $45 \mathrm{~cm}$, sudut sandaran kursi > $100^{\circ}$, sudut alas kursi $10^{\circ}$.

Hasil ujicoba produk atau penelitian tahap II yang melibatkan 6 orang ibu menyusui diperoleh hasil, penggunaan chair breastfeeding pada ibu menyusui memperoleh skor RULA 1 dan masuk level negligible risk sehingga tidak beresiko menimbulkan kelelahan pada saat proses menyusui dan bisa dikatakan chair breastfeeding ergonomic digunakan pada ibu menyusui. 5 dari 6 orang ibu mengatakan chair breastfeeding nyaman digunakan dalam proses menyusui, dan 1 orang mengatakan tidak kurang nyaman digunakan dalam proses menyusui. 
F N Safitri, T Isnawati, A Hermawan, Y P Rani, H D Aprilina | Penelitian dan Pengembangan Chair Breastfeeding untuk Meningkatkan Kenyamanan Proses Menyusui

\section{PEMBAHASAN}

Menurut teori posisi menyusui dengan duduk yang tegak pada sandaran kursi, lengan bersandar pada sandaran lengan, serta duduk dengan kaki berpijakan, akan mengurangi penumpukkan asam laktat yang membuat nyeri dan kelelahan saat menyusui. Penggunaan chair breastfeeding yang nyaman akan membantu pelekatan menyusi yang benar akan menstimulasi kelancaran aliran ASI, sehingga menghilangkan rasa kram yang muncul saat menyusui karena hormon daam refleks let-down berupa oksitosin (Wignjosoebroto, 2003).

Keergonomisan chair breastfeeding terhadap ibu menyusui saat proses menyusui mempengaruhi keefektifan ASI eksklusif serta memberikan dampak menurunkan asam laktat sehingga berkurangnya rasa nyeri, mempertahankan posisi ibu menyusui sehingga tidak mudah lelah. Kegagalan dalam proses menyusui sering kali disebabkan oleh kesalahan posisi tubuh saat menyusui sehingga menyebabkan nyeri pada leher, pinggang, lengan, dan lecet pada bagian puting (Sudarmiati, 2012).

$$
\text { Chair breastfeeding hasil }
$$
pengembangan peneliti terbukti ergonomis dengan skor RULA 1 dan masuk level negligible risk sehingga tidak beresiko menimbulkan kelelahan pada saat proses menyusui. Hal ini dikarenakan chair breastfeeding hasil pengembangan terdapat pijakan kaki yang menempel permanen pada kursi, sandaran punggung dan sandaran lengan yang dilapisi busa dan tertutup oleh kain katun halus sehingga membuat posisi duduk ibu $90^{\circ}$.
Penambahan setengah lingkaran di bagian depan yaitu untuk meringankan beban tangan ibu saat menyusui, tanggan ibu saat menyusui membuat skor RULA menjadi +2 sehingga menimbulkan kelelahan pada tangan, dan dengan menambahkan setengah lingkaran padabagian kursi, tangan ibu tidak perlu menopang bayi terlalu kuat sehingga resiko kelelahan dapat terkurangi (Lisdiana, 2013).

Ukuran chair creastfeeding juga disesuaikan dengan ukuran antropometri tubuh sehingga lebih ergonomis. Chair Breastfeeding hasil pengembangan juga terbuat dari bahan yang berkualitas, berkontribusi kuat, bagus dan menarik. Pada variable kenyaman juga memperoleh hasil 5 dari 6 orang ibu mengatakan chair breastfeeding nyaman digunakan dalam proses menyusui, dan 1 orang mengatakan tidak kurang nyaman digunakan dalam proses menyusui, sehingga chair breastfeeding sangat direkomendasikan untuk ibu menyusui.

\section{KESIMPULAN DAN SARAN}

Chair

breastfeeding hasil pengembangan terbukti ergonomis serta terbukti dapat meningkatkan kenyamanan dalam proses menyusui. Hendaknya bagi ibu menyusui menggunakan chair breastfeeding hasil pengembangan ini sehingga diporoleh kenyaman dalam proses menyusui. Pengembangan chair breastfeeding tidak berhenti sampai disini, perlu pengembangan dan pengukuran terhadap variable-variabel lain sehingga di dapatkan chair breastfeeding sempurna untuk menunjang proses menyusui. 
F N Safitri, T Isnawati, A Hermawan, Y P Rani, H D Aprilina | Penelitian dan Pengembangan Chair Breastfeeding untuk Meningkatkan Kenyamanan Proses Menyusui

\section{DAFTAR PUSTAKA}

Abdurrahmat, F. (2011). Metodologi Penelitian dan Teknik Penyusunan Skripsi. Jakarta : PT.Rineka Cipta

Dall'Oglio, I., Salvatori1, G., Bonci, et al (2007). Breastfeeding Promotion in Neonatal Intensive Care Unit: Impact of a New Program Toward a BFHI for High-Risk Infants. Acta Pædiatrica , 96: 1626-1631

Fahma, Farikhrina, dkk. (2010). Perancangan kursi untuk ibu menyusui berdasarkan pendekatan antropometri. National Conference on Appliced ergonomis.

Karwowski, Waldemar dan William S. Marras. Ed, (2006). Principles And Application in Engineering Series Occupational Ergonomics Engineering and Administrative Controle. Florida: CRC Press

Kemenkes RI. (2004). Keputusan Menteri Kesehatan Republik Indonesia Nomor 450/MENKES/IV/2004 tentang pemberian Air Susu Ibu (ASI) secara Eksklusif pada bayi di Indonesia. Jakarta: Kemenkes

Lisdiana, Sri. (2013). Pengaruh Penggunaan Kursi Ergonomis Terhadap Kenyamanan Posisi Duduk pada Ibu Menusui Bayi Usia Sampai Enam Bulan di Kelurahan Pisangan Kecamatan Ciputat Timur Kota Tangerang Selatan. Jakarta : UIN

Lowdermilk, Cashion, Perry. (2013). Keperawatan Maternitas Edisi 8. Singapore: Elsevier Morby.

McAtamney, L \& Nigel Corlett, E. (1993). RULA: a Survey Method For the Investigation of Work-related Upper Limb Disorders. Appl Ergon. Apr;24(2):91-99.

Rinata E, Rusdyati T, Sari PA. (2016). Teknik Menyusui Posisi, Perlekatan Dan Keefektifanmenghisap - Studi Pada Ibu Menyusui Di Rsud Sidoarjo. Temu IImiah Hasil Penelitian dan Pengabdian Masyarakat AIPKEMA

Roesli, U. (2000). Mengenal ASI Eksklusif. Jakarta: Trubus Agriwidya

Sudarmiati S. (2012). Pengetahuan lbu Primipara tentang Faktor-faktor yang Dapat Mempengaruhi Produksi ASI. Jurnal Nursing Studies. 1(1)
Sugiyono, (2009). Metode Penelitian Pendidikan Pendekatan kuantitatif, kualitatif, dan $R$ \& $D$. Bandung: Alfabeta

Sukmadinata. (2011). Metode Penelitian Pendidikan. Bandung: Remaja \& Osdakarya

Suradi, R. (2004). Manajemen Laktasi. Jakarta: Perkumpulan Perinatologi Indonesia.

Suryabrata, S (2012). Metodologi Penelitian. Jakarta: PT. Raja Grafindo Persada

Wignjosoebroto S. (2003). Ergonomi, Studi Gerak \& Waktu (Teknik Analisa untuk Produktifitas Kerja), Edisi Kedua. Jakarta: PT. Guna Widya

World Health Organization/UNICEF. (2011). Pelatihan Konseling Menyusui Modul 40 jam WHO/UNICEF. WHO/UNICEF 